\title{
Uma análise histórico conceitual dos megaeventos esportivos e seus desdobramentos na cidade contemporânea
}

\author{
Marcelo Andreoli. Universidade Federal do Rio de Janeiro, Rio de Janeiro, Brasil. \\ Tomas Moreira. Pontifícia Universidade Católica de Campinas, Campinas, Brasil.
}

RESUMo |A desregulamentação econômica em países mais desenvolvidos e a crescente internacionalização do capital contribuíram para emergência dos processos globais, definindo uma nova conjuntura para cidades. Neste contexto o planejamento estratégico, os Grandes Projetos Urbanos e os Megaeventos esportivos tornam-se ferramentas de um discurso hegemônico, com benefícios pautados sobre um cenário global competitivo. O desenvolvimento do pensamento acerca dos Megaeventos esportivos nos remete a questóes para compreensão deste fenômeno enquanto política de reestruturação urbana. O presente artigo discute os conceitos de Grandes Projetos Urbanos e Megaeventos esportivos para a construção da imagem Olímpica. Dentre os resultados destacam-se os Grandes Projetos Urbanos como estruturas diferenciadas na malha urbana, pois não representam o suprimento das necessidades de uma população real, mas desenvolvem demandas virtuais assumindo características de política urbana. O trabalho conclui que a estruturação das cidades tem sido transferida para as forças privadas que carecem de alternativas para construção da justiça urbana.

PALAVRAS-CHAVE | competitividade urbana, gestão urbana, transformações sócioterritoriais.

ABSTRACT | Economic deregulation in most developed countries and increasing internationalization of capital have contributed to the emergence of global processes, defining a new environment for cities. In this context, strategic planning, Mega Urban Projects, and Mega-Sports events have become tools of a hegemonic discourse, being associated with benefits within a competitive global scenario. The development of thinking on Mega-Sports events leads us to questions the understanding of this phenomenon as a policy of urban restructuring. This article discusses the concepts of urban mega projects and mega-sports events regarding the construction of an Olympic image. Among the results, it has been found that urban mega projects represent differentiated structures within the urban context, as they do not support the fulfillment of the needs of the real population, but rather develop virtual demands. The paper concludes that the determination of the structure of cities has been transferred to the private sector forces that lack alternatives for the urban construction of social justice.

KEYWORDS | urban competitiveness, urban management, socio-territorial transformations.

Recibido el 29 de agosto de 2013, aprobado el 3 de febrero de 2014

E-mail: Marcelo Andreoli, marcelocandreoli@gmail.com | Tomás Moreira, tomas.moreira@puc-campinas.edu.br

Correspondencia: Faculdade de Arquitetura e Urbanismo - UFRJ, Av. Pedro Calmon, n 550 - Prédio da Reitoria, Departamento de Projeto de Arquitetura (DPA), $5^{\circ}$ andar - Cidade Universitária, Rio de Janeiro, Brasil 


\section{A introdução do conceito: um histórico de Grandes Projetos Urbanos}

Após a Segunda Guerra Mundial os Estados Unidos assumiram uma postura de hegemonia econômica mundial, advinda principalmente de sua vitoriosa empreitada bélica, assim como do sucesso de sua iniciativa na regulamentação monetária internacional. Neste momento um novo cenário capitalista se fortalece pela de participação do Estado enquanto regulador da economia e fomentador de um desenvolvimento econômico promovido, majoritariamente por meio de políticas fiscais e financiamentos públicos (Maia, 2011).

A ordem de crescimento da produção industrial, baseada no modelo Fordista-Keynesiano (Harvey, 1992,p. 119) estabeleceu-se até o início dos anos 70, quando uma nova condição mundial passou a vigorar. Em decorrência da reconstrução europeia, ascensão do Japão no cenário produtivo, aumento da competitividade, declínio econômico norte-americano, quebra da base dólar e crise do petróleo, até então principal insumo energético, estabeleceu-se um cenário de estagnação econômica cuja consequência foi a reestruturação internacional que deu fim ao ciclo produtivo vigente até então.

As transformaçōes sofridas nos anos 70 tornaram-se fundamentais para a compreensão dos acontecimentos mundiais das décadas subsequentes, de 80 e 90, pois representaram uma ruptura no modelo produtivo, inserindo novos cenários econômicos para a manutenção do capitalismo, e consequentemente uma nova condição social passou a ser construída.

Alguns aspectos sócio-políticos tomam especial atenção na explicação e compreensão de fenômenos posteriores, que garantiram o declínio das políticas de bem-estar social do pós-guerra e a "reciclagem dos princípios liberais" (De Oliveira, 2009, p. 3). Dentre eles, destacam-se a decadência de antigos polos industriais e a adoçáo do planejamento estratégico, em detrimento do planejamento tradicional. As transformaçôes urbanas fizeram emergir a condição mercantil das cidades, principalmente nas grandes metrópoles, que concentravam o capital produtivo. $\mathrm{O}$ cenário de precedência da instância política sobre a econômica ganha agora novas configuraçôes, concebidas pelo alinhamento das lógicas das grandes empresas, internacionais ou nacionais, com a política interna ou internacional de cada país (Santos, 2008, p. 255).

Neste processo de transformaçóes, que se refletem também territorialmente, os antigos polos industriais são afetados pelas novas dinâmicas sociais. Há um acréscimo de pessoas envolvidas no setor terciário em países de capital desenvolvido, e um excedente de mão de obra industrial em países com o capitalismo menos desenvolvido. A despeito disto, ocorreu naturalmente a expansão das unidades produtivas para os países periféricos, e a consequente derrocada da base industrial em países centrais.

Neste cenário de reestruturação político-social mundial, de desemprego na Europa devido ao declínio de seu polo industrial, de déficit econômico e altas taxas de inflação, e os Estados Unidos ainda se reestabelecendo da crise econômica de 73, uma nova dinâmica de combate a crise foi imposta, principalmente nos governos de Margaret Thatcher e Ronald Reagan.

Os impactos das novas configuraçóes sociais se reproduzem fisicamente na malha das cidades. Entre as diversas expressôes urbanas deste período, a reutilização de áreas industriais se intensifica a fim de alavancar novos usos para espaços que 
tornaram-se degradados ou subutilizados ao longo dos últimos 25 anos (Somekh \& Campos, 2005, p. 1).

Em face destas políticas neoliberais, o planejamento estratégico surge como ferramenta de reformulação de cidades que buscavam soluçóes imediatas para suas novas problemáticas urbanas, passando a privilegiar os ganhos em curto prazo em detrimento das modificaçóes em um longo período. A emergência de uma nova condição, na qual o capital privado e a flexibilização urbana se associam ao inchaço do setor terciário, promoveram a expansão imobiliária enquanto ferramenta de regulação urbanística, assim como um instrumento rentável para grupos investidores, favorecendo uma ideia de eficiência do novo modelo de planejamento urbano. Com isso o planejamento estratégico se fortalece como discurso crítico em relação ao planejamento urbano tradicional (Güell, 1997), compartilhando de elementos da gestão administrativa empresarial dentro da escala urbana e estabelecendo-se sobre políticas de marketing urbano.

A considerada limitação dos modelos tradicionais de planejamento de cidades em oferecer suporte aos possíveis novos investimentos e as transformaçóes urbanas exigidas, contribui para a defesa de um planejamento estratégico como único meio eficaz frente aos novos processos de globalização. A ênfase na competição urbana é, portanto, uma das condicionantes neste processo, no qual o Estado torna-se ator responsável pela promoção da cidade, considerado saudável na medida em que municípios competem para atração de investimentos e fomentam o crescimento de cidades globais numa totalidade (Güell, 1997). Ao mesmo tempo, os processos de competição global pela busca de investimentos, instauram a "guerra entre os lugares, expressão emblemática da subsunção do mundo e da vida contemporâneos à lógica do capital nesses tempos de desmedia empresarial" (Sánchez et al, 2004, p. 42).

A condição exposta acima demonstra a crítica ao modo de apreensão do modelo estratégico de planejamento, no qual a competição urbana evidencia um desenvolvimento territorial desigual (Lungo, 2005), privilegiando as elites financeiras da sociedade, que se tornam capazes de usufruir do novo espaço comercializado, enquanto que o planejamento urbano encontra-se cada vez mais omisso aos problemas estruturais da sociedade.

A compreensão da necessidade da inclusão em um mercado globalmente competitivo exige das cidades medidas de atração de capitais, utilizando-se de parcerias reconhecidas pela associaçáo dos interesses do estado com os interesses da iniciativa privada. A concepção destas parcerias público-privadas, e da condição de unificação de interesses, estabelece a cooperação entre atores edificando a base do pensamento de um "Projeto de Cidade" (Castells \& Borja, 1996). Porém, a incorporação de novos atores aos processos urbanos, buscando o resultado financeiro promovido pela exposição da cidade através do "marketing urbano", reduz a construção social-histórica a um elemento mercantilizado no qual a cidade torna-se mercadoria e o direito à cidade passa a ser proporcional ao índice de solvência da população (Vainer, 2000, p. 78).

A cidade considerada sobre bases comerciais torna-se um objeto lucrativo em que procedimentos de city marketing são essenciais para a reprodução dos investimentos. Esta postura, fruto de uma relação público privada, desenvolve um novo método 
de gestão urbana, chamado por Harvey (1996) de empresariamento urbano. Reconhecido pela capacidade de dinamizar investimentos e promover desenvolvimento econômico por meio da compreensão de problemas pontuais, o empresariamento urbano propóem um olhar parcelar sobre a cidade orientado para práticas especulativas de reestruturação de áreas, fortalecendo uma cidade com direcionamentos de recursos assimétricos (Malengrau, 2013), transformando-as em palcos de competição na busca pela atração de investimentos.

Em um contexto competitivo a construção de ícones arquitetônicos eleva o poder simbólico da cidade, desenvolvendo sentimentos ufanistas patrióticos, além de criar imagens que contribuem com o apaziguamento de revoltas. Conforme anunciado por Debord (1997), "as simples imagens tornam-se seres reais e motivaçôes eficientes de um comportamento hipnótico” (p. 18).

Neste momento os Grandes Projetos Urbanos (GPU) constituem-se como ferramentas redentoras de cidades em decadência. Governos locais se apropriaram deste instrumento para reestruturação de espaços degradados encontrando no mercado imobiliário fortalecido e no inchado setor terciário alternativas para desenvolvimento.

Antigas áreas industriais obtiveram especial atenção com a promoção dos GPUs (Grandes Projetos Urbanos), representando uma nova centralidade urbana, como nos casos clássicos de Baltimore (Inner Harbor), Londres (London Docklands), Battery City (Nova Iorque) e Barcelona (Jogos Olímpicos). Também classificados dentro de uma cultura de apropriação pós-moderna (Harvey, 1992), os GPUs, quase sempre, se apresentam procurando atrair novos investimentos e atividades econômicas. Fortalecidos pela arquitetura monumental, constituem um importante veículo para a proclamaçáo da cultura global, materializando-se por ícones urbanos através da construçáo de novos centros de negócios, comerciais e de turismo, shopping centers e hotéis sofisticados, centros de convenção, marinas, restaurantes, parques temáticos, etc.

Os GPUs tornaram-se, portanto, elementos importantes dentro de uma política global de reconhecimento e inclusão de cidades em uma rede mundial. Neste contexto a aclamada requalificação urbana almejada pelos governos, torna-se por vezes tão somente elemento de uma espetacularizaçáo da cidade, por meio da arquitetura carregada de superficialidade e de ilusória participação social (Arantes, 2000, p. 22).

Arquitetonicamente muito representativos na malha urbana, os GPUs são reconhecidos pela articulação dos atores envolvidos em seus processos de aprovaçáo e construção, como afirmam Castells e Borja (1996) quando enumeram sua "possibilidade de criar holdings, consórcios ou empresas mistas; na execução conjunta, com outras administraçôes e com agentes privados" (p. 162). O Estado tem o papel de harmonizar discursos e mediar disputas entre a população local e agentes investidores.

Muito embora os GPUsse constituam como elementos pontuais na paisagem urbana, eles podem configurar externalidades para além dos limites geográficos locais, quando pensados a partir da possível inserção em uma hierarquia mundial de cidades. Neste sentido, globalmente são considerados elementos representativos, e 
por isso contribuem com a reprodução de um sistema estabelecido, aprofundando o empresariamento urbano e criando um ambiente controverso.

Se por um lado a inserção em um mundo globalizado pode nos elevar à condiçáo de cidade detentora de poder gravitacional, concentrando, em sua grande maioria, atividades informacionais (Castells \& Borja, 1996, p. 51), por outro presenciamos a subordinação das necessidades locais aos interesses globais, acirrando as tensôes sociais e a possibilidade de ser vítima de uma "reificação desnecessária" (Harvey, 1996, p. 51), no qual a cidade transforma-se em mercadoria a ser comercializada.

O desenvolvimento deste modelo de gestão urbana estimula inevitavelmente mapas de exclusão a partir desta competição sintomática de uma sociedade do espetáculo, cujos projetos se apresentam paulatinamente mais extravagantes em um mundo desenvolvido, e ao mesmo tempo megalópoles globais tornam-se redutos da pobreza e exclusão (Frampton, 2008, p. 420).

\section{A produção tardia de Grandes Projetos Urbanos no Brasil}

No Brasil, o conceito de GPUs confunde-se em um primeiro momento com as grandes obras de infraestrutura, no entanto, embora de forma tardia, os Grandes Projetos Urbanos se estruturam sobre os novos processos econômicos e atualmente constituem parte das políticas de planejamento de cidades brasileiras. Para se compreender este cenário tardio de implementação de GPUs, é necessário reconhecer os processos que estruturam a condição sócio-política brasileira a partir, principalmente, da década de 1930, pois neste período existia um momento de avanço e euforia, devido ao início da elevação da produtividade industrial brasileira, com inúmeras políticas de fomento a indústria e a diversificação do aparelho produtivo (Furtado, 1981, pp. 29-30).

Dadas tais condiçóes, a década de 1940 representou um período da diminuição das taxas de desemprego, bem como da expansão da indústria nacional, tendo na década de 50 a fase decisiva da industrialização brasileira com a criação da Petrobrás, monopólio estatal do petróleo, e com a criação do Banco Nacional de Desenvolvimento Econômico (BNDE), com função de ampliar os investimentos em infraestrutura de transportes e energia. Nesta mesma década a adoção do Plano de Metas, no governo de Juscelino Kubistchek, foi marcante para o cenário industrial, afinal se caracterizou por uma "intensa diferenciação industrial num espaço de tempo relativamente curto" (Serra, 1982, p. 23). O crescimento proposto por Kubistchek neste período, com o famoso lema de "cinquenta anos em cinco", era buscado por meio de uma postura de altos investimentos nas indústrias de base e na abertura para investimentos internacionais através da produção de bens de consumo.

Em linhas gerais, até 1960 a base ampla do mercado nacional foi garantida a partir das políticas assumidas na era Vargas. Através de elementos protecionistas e de apoio à substituição de importaçóes, foram gerados dinamismo econômico, criadas estruturas capazes de dar suporte a produção nacional com altos investimentos estatais na promoção de energia e transportes, assim como com fortes investimentos fiscais e cambiais para a produção nacional. 
O planejamento urbano centralizador da década de 1960 alcança sua máxima representação com a transferência da capital do Rio de Janeiro para a então inaugurada Brasília. O golpe militar de Estado em 1964 instaurou uma nova percepção de governo, a ditadura militar, no mesmo período em que se encerrava a experiência do desenvolvimento industrial iniciada por Getúlio Vargas e pelo Estado Novo. A estratégia dos militares para desenvolvimento do país era baseada, principalmente, no incremento do setor de bens de consumo duráveis, o que gerou uma maior concentração de renda e o consequente acréscimo da desigualdade social.

Entretanto, os anos seguintes foram reconhecidos como o "milagre econômico" (Coriat \& Saboia, 1988, p. 9), promovidos essencialmente pelas maciças campanhas governamentais que proclamavam o acréscimo dos índices de produção nacional, crescimento econômico, industrial e pelas grandes obras governamentais. Diferentemente do período anterior, em que se buscava um desenvolvimento industrial estrutural, agora a busca pela industrialização concentrava-se no contingente de grandes obras de infraestrutura.

Neste contexto, estas grandes obras revelam um caráter de contribuição para uma integração do território nacional, pois os investimentos concentravam-se majoritariamente em projetos de transporte e conexóes viárias. Os grandes projetos deste período gozam de especial prestígio, afinal representam também a demonstração do poder militar e contribuem com a produção e reprodução de capitais, assim como determinados projetos possuem cunho de embelezamento da paisagem.

\begin{abstract}
"Grandes Obras" tomam força nos anos 70, durante o período militar, ainda com um objetivo de declaração de poder, mas com um caráter mais geopolítico, de tomada ostensiva de territórios até então não ocupados e, máxima na época nacionalista (...). Aliadas ao imaginário nacionalista, essas grandes intervenções, ao modo das atuais, transmitiam uma ideia importante para o período, que era a de "progresso" e integração de regiốes atrasadas economicamente no contexto nacional. Adotando a prática dos grandes projetos com magnitude de tamanho, escala e complexidade, o poder central esperava: a) estimular novos processos urbanos que transformariam as cidades e trariam o desenvolvimento a todo o país; e b) atender a uma política de ordenaçáo do território nacional que buscava diminuir as disparidades existentes. É nesse contexto que o regime militar brasileiro iria promover grandes obras, algumas inclusive conhecidas pelo adjetivo de faraônicas por seu tamanho e complexidade (Ultramari \& Rezende, 2007, p. 10).
\end{abstract}

Após o regime militar, em meados da década de 80 , o Brasil buscou a estabilidade econômica e só começou a obter êxito ao final dos anos 90 e início de 2000 com uma política articulada em três princípios: estímulo ao emprego formalizado, valorização dos salários e do salário mínimo e programas de transferência de renda (Mattei, 2012, p. 37). Com isso o Brasil alcançou prestígio internacional e se estabeleceu enquanto nova potência econômica mundial, reconhecido enquanto país emergente incorporando o grupo dos países BRICs.

Esta breve construção histórica e econômica do Brasil demonstra como as grandes obras se constituíram enquanto elementos da política local e se diferenciaram das iniciativas internacionais de Grandes Projetos Urbanos. Pois enquanto o 
Brasil atravessava um período de protecionismo e repressão promovidos pelo regime militar, de aparente desenvolvimento industrial e acentuação da desigualdade social, gerando uma urbanização segregada e atípica, as grandes obras emergem como uma ferramenta de controle social e demonstração da pujança do governo militar. Da mesma forma, estes projetos atuaram como elementos eficazes na estruturação de um Estado desarticulado, com ênfase, principalmente, em obras de circulação viária e transporte (Ultramari \& Rezende, 2007; Vainer, 2000).

Antagonicamente o cenário encontrado na Europa para implantação de GPUs consistia primordialmente em: situaçōes pós-guerra, novas demandas por transporte, crescimento da mancha urbana e novas demandas culturais (Powell, 2000). Assim, percebe-se que a condição de existência dos GPUs no Brasil em muito se difere da gênesis conceitual desta prática na Europa, pois se aqui os GPUs assumiam a característica de elemento urbano pautado sobre [duvidosas] demandas territoriais inerentes ao espaço local, na Europa estes projetos foram concebidos enquanto ferramentas construtoras do processo de edificação territorial em torno de estratégias de uma organização espacial-capitalista.

Transformados em elementos importantes da história recente das cidades, os Grandes Projetos Urbanos são concebidos enquanto estruturas complexas frutos de uma nova condição do Estado, na qual se privilegia o diálogo global em detrimento da escala local. Muito embora a compreensão dos GPUs seja envolta por controvérsias, as bases fundamentais da discussão devem ser compreendidas por meio de um conceito comum, para tanto é necessário o enfrentamento conceitual acerca do tema avaliando as críticas da prática recente.

\section{Reconstruindo conceitos}

Os Grandes Projetos Urbanos são atualmente reconhecidos como ferramentas de uma nova condição de planejamento urbano. Tornaram-se elementos da discussão acadêmica, sobretudo, após os casos clássicos internacionais. Entretanto, mesmo compondo uma importante vertente do pensamento atual acerca do planejamento urbano, ainda gozam de divergências conceituais, gerando grupos oposicionistas e defensores na concepção e implantação destas estruturas. Portanto, busca-se confrontar os discursos atuais acerca da prática dos GPUs, para que por meio desta avaliaçáo se possa compreender as políticas recentes, sobretudo pelo uso dos Megaeventos esportivos, de implementação destas estruturas.

A conceituação de um GPU ultrapassa os limites espaciais, físicos ou arquitetônicos do projeto, sendo entendidos, no presente trabalho, dentro de um cenário macroeconômico de acumulação de capital, edificado durante o período pós-guerra de reestruturação global, compondo uma condição pós-moderna de leitura mundial (De Oliveira \& Lima Junior, 2009; Harvey, 1992; Nobre, 2000). Inevitavelmente discurso e prática não possuem o mesmo escopo, pois, embora a defesa dos GPUs se estabeleça sobre uma retórica keynesiana de benefícios reproduzidos largamente para toda a população, a sua prática é, em grande parte, a inserção de um pensamento neoliberal na cidade contemporânea. 
Deste modo os GPUs, muito mais do que grandes estruturas urbanas com impacto imediato na malha das cidades, devem ser compreendidos enquanto condicionantes do espaço tempo, refletindo efetivamente a situação urbana de acumulação capitalista. Figuram em um cenário cuja economia "contém tanto as capacidades para uma enorme dispersão e mobilidade geográficas quanto as acentuadas concentraçôes territoriais necessárias para administração e manutenção dessa dispersão" (Sassen, 2010, p. 27), ou seja, admitem a expansão e reprodução capitalista ao mesmo tempo em que assumem posturas de concentração de investimentos, desenvolvendo cidades com características globais.

As transformações recentes experimentadas pelo sistema capitalista, definindo a nova reestruturação mundial em torno de questóes produtivas e sociais, geraram inevitáveis impactos nas cidades. Conforme afirmam Castells e Borja (2004, p. 49), "o novo espaço industrial se organiza em torno de fluxos de informação, separando e reunindo seus distintos componentes territoriais, segundo os ciclos e segundo as empresas". Desta forma, o espaço antes materializado por meio das plantas industriais agora se encontra dissipado em meio ao fluxo informacional, conduzindo ao abandono áreas da cidade nas quais a consequente reocupação torna-se alternativa para readequação destas áreas degradadas.

A produção de um cenário determinado por redes de cidades (Santos, 2008) introduziu novos desafios também na menor escala urbana. Frente a este novo cenário econômico mundial se destaca a importância de um posicionamento estratégico global por parte das cidades, em vista de possíveis investimentos, assim como para alcançar patamares mais elevados no mercado competitivo internacional.

Para tanto, os Grandes Projetos Urbanos atuam como dinamizadores espaciais transescalares, de acordo com Lungo (2011, p. 5), "redefinindo o papel das cidades e colocando a questáo da competitividade da mesma” Sánchez et al. (2004). Também enumeram esta condição das cidades em incorporar tendências do fenômeno da globalização por meio de elementos "produzidos com vistas à ampliaçáo de sua inserção no circuito mundial de valorização".

Desta forma fica evidente a constituição imagética dos GPUs enquanto elementos necessários para a efetivação da competitividade local no cenário global. Todavia, a própria condição de impacto imediato na malha urbana já constitui uma justificativa para o uso desta ferramenta como componente que apresenta “(...) a qualidade espacial e urbanística (...) de renovação, redefinindo a hierarquia urbana em favor da região antes degradada” (Somekh \& Campos, 2005, p. 3).

São exaltados como ferramentas constituintes desta condição de renovação urbana, devido ao processo de possível reestruturação de espaços degradados como observado nos casos de Baltimore, Londres, Barcelona e Bilbao. A reestruturação promovida por meio da implantação de GPUs deve-se, também, à representação simbólica intrínseca à própria estrutura. Construindo elementos significativos para os cidadáos, os GPUs têm em sua base conceitual, conforme Bonates (2009), a característica de "arquitetura monumentalista" (p. 62).

Esta condição monumental assumida pelos GPUs é assinalada enquanto elemento necessário para a representação simbólica, pois cria uma relação ufanista entre cidadãos e cidade (Vainer, 2000, p. 94), concedendo ao projeto demasiada importância 
face ao planejamento e consequentemente transformando-o numa mercadoria por ele mesmo (Sánchez et al., 2004, p. 43). Desta forma, os GPUs representam não somente a construção da estrutura simbólica da cidade, mas passam também a representar um elemento comercial com valor inerente.

Muito embora os GPUs sejam ferramentas largamente utilizadas com objetivos variados, eles ainda náo gozam de pleno consenso acadêmico, principalmente por conta das divergências acerca da suas reais consequências no tecido urbano. Se por um lado somos compelidos a crer no papel modificador destas estruturas sócio espaciais (Castells \& Borja, 2004; Guell, 1997; Lerner, 2003), somos, ao mesmo tempo, desacreditados pelas teorias oposicionistas (Lungo, 2011; Harvey, 1996; Sánchez, 2004; Vainer, 2000). Destaca-se nesses debates também leituras realizadas por uma ótica histórica. Esta visão compóe o elemento comum dentro da dualidade entre oposicionistas e defensores com avaliaçóes puramente referentes aos processos de produção dos Grandes Projetos Urbanos (Nobre, 2000; Ultramari \& Rezende, 2007).

Como representação sistemática destas divergências conceituais, o Quadro 01 organiza pontualmente os argumentos de análise dos GPUs, e apresenta formalmente como a visão historicista embasa as duas leituras antagônicas acerca do tema.

\section{QUADRo I | Análise teórica acerca dos GPUs}

\begin{tabular}{|c|c|}
\hline DEFENSORES & OPOSITORES \\
\hline $\begin{array}{l}\text { 1. Contribuição com processos de requalificaçáa } \\
\text { de áreas degradadas; }\end{array}$ & $\begin{array}{l}\text { 1. Possíveis efeitos de eletrização e consequente } \\
\text { gentrificação de áreas; }\end{array}$ \\
\hline $\begin{array}{l}\text { 2. Inserção da cidade num circuito global de } \\
\text { valorizaçáo; }\end{array}$ & $\begin{array}{l}\text { 2. Subordinação das necessidades locais aos inte- } \\
\text { resses globais; }\end{array}$ \\
\hline $\begin{array}{l}\text { 3. Maior competitividade na busca por investi- } \\
\text { mentos; }\end{array}$ & $\begin{array}{l}\text { 3. Geraçáo da guerra dos lugares, na qual o merca- } \\
\text { do determina os investimentos; }\end{array}$ \\
\hline $\begin{array}{l}\text { 4. Coalizão de diversos interesses dentro de um } \\
\text { único plano; }\end{array}$ & $\begin{array}{l}\text { 4. Apropriação do planejamento urbano por parte } \\
\text { de grupos privados, abarcando, sobretudo, seus } \\
\text { interesses; }\end{array}$ \\
\hline 5. Possível integração como um plano de cidade. & $\begin{array}{l}\text { 5. Projetos pontuais, sem a compreensáo da totali- } \\
\text { dade da cidade. }\end{array}$ \\
\hline \multicolumn{2}{|c|}{ HISTORICISTAS } \\
\hline \multicolumn{2}{|c|}{ 1. Projetos frutos de um processo de reestruturaçáo do sistema capitalista; } \\
\hline \multicolumn{2}{|c|}{ 2. Construçôes necessárias no período pós-guerra para a reconstrução das cidades; } \\
\hline \multicolumn{2}{|c|}{ 3. Períodos de flexibilizaçao do capital contribuíram com o desenvolvimento destas políticas; } \\
\hline \multicolumn{2}{|c|}{$\begin{array}{l}\text { 4. Sáo identificados como elementos de uma política econômica global que surgiu nos anos } 70 \text { passan- } \\
\text { do por renovaçóes contínuas até os dias atuais; }\end{array}$} \\
\hline \multicolumn{2}{|c|}{ 5. Uma das condições da concepção do estado pós-moderno. } \\
\hline
\end{tabular}

FONTE ELABORAÇÃO PRÓPRIA

A construção de um corpo conceitual sobre GPUs orienta uma possível classificação do objeto de estudo acerca da sua prática. No entanto a aplicabilidade destes conceitos em uma realidade em movimento, somente torna-se possível a partir da introdução de uma classificação precisa sobre o tema.

Portanto uma vez compreendido que a avaliação de GPUs não se determina somente pela sua extensão ou tipologia, mas deve-se considerar, sobretudo, o seu 
impacto direto sobre a estrutura e desenvolvimento da cidade (Lungo, 2004). Propóe-se a ampliaçáo deste conceito relacionando a concepção de GPUs às práticas de acumulação capitalista em um cenário global. Considera-se portanto que, por meio da implantação destes projetos ocorre o desenvolvimento de demandas locais e internacionais na cidade. Neste processo os atores e benefícios gerados por tais estruturas extrapolam os limites da cidade, e possuem um alcance mundial, configurando um importante vetor de expansão imagética para a cidade.

A luz destes pressupostos acerca da emergência de GPUs, os Megaeventos esportivos se apresentam enquanto ferramentas ativas deste cenário contemporâneo de gestão urbana. Pois se apresentam como estratégias deliberadas para fomento da economia, calcado sobre um arcabouço teórico que sustenta a concentração de investimentos na cidade (Oliveira, 2011, p. 20). Desta maneira os Megaeventos esportivos tornam-se expressão emblemática da produção atual de uma gestão urbana estratégica baseada na construção de Grandes Projetos Urbanos.

\section{A nova gestáo com os Megaeventos}

Os Megaeventos esportivos são expressóes materiais com características efêmeras, "cada Megaevento permite a consolidaçáo de uma determinada temporalidade geracional" (Seixas, 2010, p. 6), tornando-se elemento de um momento específico na história das cidades. Desta forma, são compreendidos dentro de um ponto preciso na linha do tempo, muitas vezes importantes pelas inflexóes urbanas que geram.

A compreensão da emergência dos Megaeventos apoia-se sobre as modificaçôes sócio-políticas mundiais experimentadas pela sociedade nas últimas décadas. Esta nova configuração acabou transformando-os em verdadeiros agentes políticos (Seixas, 2010, p. 5), representando uma ferramenta eficaz não somente pelos impactos efetivos na malha urbana, mas também pela contribuição no reposicionamento de cidades na hierarquia global.

Neste cenário que envolve, sobretudo, uma política de projetos pontuais com impactos mais imediatos, os Megaeventos se destacam enquanto prática atual e solução "imediata" para a construção de estruturas simbolicamente representativas, atuando por meio de uma hegemonização dos discursos.

Historicamente as grandes intervenções urbanísticas e os eventos esportivos estiveram presentes no desenvolvimento de cidades. Como observado por Seixas (2010, p. 7), "sempre existiram projetos de referência (desde as manifestaçóes de opulência da Roma antiga e passando pelos projetos urbanísticos racionalistas dos séculos XVIII e XIX)". Entretanto estas práticas no ambiente contemporâneo se reconstroem sobre outros discursos, que outrora não se justificavam em um regime de acumulação, novos processos industriais, modos de regulação e novos cenários geográficos globais.

Em face destes acontecimentos globais, os Megaeventos esportivos encontram sua justificativa dentro do cenário atual competitivo, no qual os GPUs se materializam como estratégia de ação. Em um primeiro momento estes Megaeventos se constituem apenas como "engrenagem estabelecida no planejamento estratégico" (Oliveira, 2011, p. 19), mas com tempo se consolidam como prática de uma nova condição urbana, estabelecida no núcleo conceitual do planejamento estratégico e dos GPUs. 
Neste cenário a "sociedade do espetáculo" (Debord, 1997) constituiu a representação material das transformações experimentadas, na qual "o espetáculo é o capital em tal grau de acumulação que se torna imagem” (p. 25). A constituição de uma sociedade do espetáculo se assemelha a gênese dos GPUs quando assumem valor de produto intrínseco à própria estrutura, ou seja, representando a valorização pela simples existência. Esta condição fortalece as críticas relacionadas a implantação dos Megaeventos enquanto estruturadores da cidade, uma vez que "a produção do espaço é definida então pelo valor de troca, pelo posicionamento destes diante do mercado" (Raeder, 2010, p. 8), ou seja o espaço transforma-se em mercadoria valiosa e obtém a sua valorização a partir dos produtos inseridos na paisagem.

A valorização dos novos espaços urbanos, promovidos como elementos necessários para o city marketing eleva as cidades proponentes a sedes de Megaeventos ao concorrido cenário global de competitividade urbana. Se por um lado este ingresso é apresentado com uma ferramenta de "redenção" (Short, 2008, p. 324) de cidades decadentes, promovendo verdadeiras renovaçóes urbanas por meio da captação de investimentos públicos e privados, por outro avaliamos a tendência a subordinação local aos interesses globais, permitindo a mercantilização dos espaços urbanos e a consequente "guerra dos lugares" (Sánchez et al., 2004, p. 42).

A ocorrência de um Megaevento se realiza dentro de um cenário abstrato de possibilidades para determinada cidade, tendo a sua materialização efetuada somente por meio de estruturas representativas no espaço urbano. Nesta condição, a "arquitetura espetacular" (Broudehoux, 2011, p. 41) é percebida enquanto elemento corrente na formatação dos Megaeventos, sendo ao mesmo tempo recoberto por uma gama de benefícios e, de forma antagônica, sendo também duramente criticado.

A representaçáo espacial necessária para atendimento da demanda de um Megaevento é apresentada como elemento eficaz na reconstruçáo do território, valorizando-o por meio dos investimentos realizados no local, assim como pela própria característica de valorização do "produto" que ali se implanta. A consolidação de projetos resultantes de Megaeventos podem se tornar propulsores de uma possível requalificação urbana. Para tanto, é necessário a "inclusão destas estratégias (...) no planejamento urbano integrado da cidade” (Seixas, 2010, p. 8).

A proposta de dinamização de áreas na cidade encontra-se como uma das justificativas para a adoção de Megaeventos na gestão urbana, pois representam, assim como os GPUs, estruturas simbolicamente fortificadas pelo próprio caráter monumental que assumem, tendo em sua implantação a recriação dos laços e da relação de lugar com o espaço. A recriação da paisagem na produção de Megaeventos por meio da arquitetura monumentaldesenvolve um cenário de valorização idealizada absoluta, conduzindo a um "patriotismo de cidade" (Vainer, 2000, p. 94), que tem em sua retórica a intolerância por posições contrárias a implantação do evento.

Ao passo que a monumentalidade se faz presente na produção do Megaevento, elevando o poder do impacto positivo, também a adoção de "Megaprojetos" (Seixas, 2010 , p. 8) nos remete a críticas quanto a sua retórica de benefícios. Recobertos com um discurso patriótico, os Megaeventos assumem uma postura benéfica na qual as grandes estruturas tornam-se ícones legítimos de poder aumentando a visibilidade do Estado na paisagem, "os espaços monumentais e a arquitetura espetacular atuam 
(...) a serviço de ideologias do Estado e moldam a experiência humana por meio da manipulação de objetos e símbolos" (Broudehoux, 2011, p. 40).

Neste cenário a arquitetura espetacular representa, portanto, a hegemonia do discurso em que, segundo Vainer (2000; p. 96), ocorre a "despolitização planejada", momento no qual as necessidades básicas do cidadão têm liberdade para serem olvidadas em face das características megalomaníacas que os projetos assumem. Neste sentido o espetáculo promove uma remoção da realidade (Broudehoux, 2011, p. 43) das perspectivas da vida cotidiana, ou seja, através destas imagens e signos o Estado permite criar sentimentos de ordem e pacificação, desviando o foco dos problemas sociais mais latentes.

A produção de ícones arquitetônicos encontra significado dentro do complexo sistema internacional de acumulação de capital, bem como encontra aliados econômicos e políticos por causa das transformaçôes sofridas pelas cidades. Neste cenário as parcerias público-privadas emergem como elemento aglutinador de interesses entre governos locais e a iniciativa privada. A conformação destes interesses sustenta-se sobre princípios liberais, reunindo elementos para a justificação da competição urbana e da mercantilização da cidade promovida de forma relevante pelo "desenvolvimento do city marketing, ou mesmo do branding urbano" (Seixas, 2010, p. 7).

Concebidos quase sempre pela iniciativa governamental e amparados pelos investimentos públicos e privados, os Megaeventos tornaram-se símbolo de uma nova condição da gestáo urbana, principalmente pelos impactos causados pela implantaçáode suas estruturas, que partem de uma retórica de um planejamento integrado, representando uma melhora verdadeira para a cidade. Entretanto, as críticas assumidas pela adoção de um Megaevento partem de uma postura cética quanto a sua real capacidade de reforma urbana, visto que a valorização do projeto assume características elevadas frente aos benefícios às cidades e este toma valor pela própria existência, tornando-se mais "valiosos" e representativos do que a cidade que o abriga.

Ainda que a celebração dos Megaeventos possa conduzir aos mais variados impactos positivos, não se deve ignorar uma análise mais aprofundada acerca das críticas da sua utilização. A adoção dos Megaeventos como ferramentas de reconfiguração urbana pode, em determinados cenários, ser compreendida em meio a novas lógicas de gestáo que permitam o surgimento de elementos urbanos benéficos para toda a população, a partir do debate social. Ao mesmo tempo, a manutenção de uma gestão de Megaeventos pautados sobre aspectos neoliberais de acumulação de capital tende a favorecer a execução de projetos sem reflexóes acerca de um planejamento composto de princípios de direito à cidade enquanto diretriz estrutural. Compondo iniciativas pontuais descontextualizadas da malha urbana, cujos benefícios encontram-se restritos a uma parcela restrita da população, que é capaz de apropriar-se dos resultados imagéticos e imobiliários gerados pelas estruturas e pela realização do evento.

Neste cenário, os Jogos Olímpicos configuram um dos maiores exemplos atuais de concepção de Megaeventos com escopo esportivo, afinal possuem sua dimensão simbólica enquanto evento e marca revendida ao redor do mundo, e, portanto, caracterizando-o como ferramenta de alcance mundial para o reconhecimento de cidades dentro de uma hierarquia global. Assim como promovem verdadeiras 
reformas urbanas, com impactos diversos, sobre as cidades sedes por conta das infraestruturas necessárias para o recebimento do Megaevento.

\section{A construção da imagem Olímpica}

Muito embora a tradição olímpica remonte aspectos da tradição esportiva remota, buscando na Grécia antiga elementos para realização dos Jogos Olímpicos atuais, o cenário contemporâneo de realização destes eventos ultrapassa aqueles conceitos puramente esportivos, assumindo outras características devido ao demasiado impacto realizado em diversos áreas e setores da sociedade. Desta forma, as Olimpíadas atuais destacam-se como catalisadores de projetos urbanos de desenvolvimento em cidades sedes, necessitando uma amplitude de equipamentos urbanos para a sua efetiva realização.

As Olimpíadas da era moderna foram concebidas sobre os ideais do nobre francês Pierre de Fredi, o Barão de Coubertain, que acreditava que os Jogos Olímpicos da antiguidade grega poderiam ser reavivados com uma roupagem moderna (Freire \& Ribeiro, 2006, p. 34). Foi quando em 1894 a Conferência Internacional de Paris estabeleceu, com base nos pensamentos de Coubertain, as diretrizes para a realização do primeiro evento Olímpico da era moderna, realizado na cidade de Atenas em 1896. Nesta mesma ocasiāo foi criado o Comitê Olímpico Internacional, entidade máxima do esporte Olímpico.

Ao longo da história os Jogos Olímpicos vêm sendo reproduzidos sobre a retórica do "Olimpismo", cujo discurso baseia-se em valores de igualdade, paz, harmonia, democracia e o equilíbrio entre o corpo e com a mente (Freire \& Ribeiro, 2006, p. 36). Este discurso tornou-se necessário para o sucesso da reprodução do evento, uma vez que esta retórica de valores humanos e esportes estabeleceu parcela importante para consolidação da marca olímpica, cristalizando os Jogos como novo ideal esportivo no mundo e desenvolvendo-se como prática cada vez mais cristalizada ao longo dos anos.

A evolução dos Jogos Olímpicos desde sua primeira edição, em 1896, demonstra a crescente universalidade do evento, que somou nas últimas ediçóes mais de 200 países participantes, 30 modalidades esportivas e mais de 10.000 atletas. Destaca-se também nesta leitura a concepção dos Jogos Olímpicos do Rio de Janeiro, em 2016, que confirmaráo a passagem deste Evento pelos cinco continentes.

Contudo, se por um lado observa-se o pleno crescimento dos Jogos Olímpicos demonstrado pelas dimensóes que alcançam recorrentemente, devido ao contingente cada vez maior de países, atividades e atletas. Entretanto, por outro lado, o impacto gerado em cidades sede por este crescimento, cuja materialização ocorre por meio dos equipamentos esportivos e é absorvido como ferramenta de planejamento urbano, ainda carece de reflexóes principalmente quando avaliados face aos períodos de pensamento vigente. Para o entendimento da reprodução desta prática de gestão urbana utilizando a implantação dos Jogos Olímpicos é necessário compreender o modo como se desenvolveu a retórica acerca desta concepção, conforme destaca o Quadro 2. 
QUADRo 2 | Desenvolvimento histórico dos Jogos Olímpicos

\begin{tabular}{|c|c|c|}
\hline \multirow{2}{*}{ 1a FASE } & 1896 & \multirow{2}{*}{ Edições com baixos investimentos e poucas intervenções urbanas } \\
\hline & 1904 & \\
\hline \multirow{2}{*}{ 2a FASE } & 1908 & \multirow{2}{*}{$\begin{array}{l}\text { Instalaçôes esportivas mais imponentes do que no período anterior } \\
\text { ganhando maior destaque na malha urbana. Em } 1936 \text { é construída a } \\
\text { primeira Vila Olímpica para atletas. }\end{array}$} \\
\hline & 1936 & \\
\hline \multirow{2}{*}{ 3a FASE } & 1948 & \multirow{2}{*}{$\begin{array}{l}\text { Fase de austeridade promovida pelo período pós-guerra, sofrendo } \\
\text { com restriçóes orçamentárias os equipamentos esportivos mostram-se } \\
\text { modestos }\end{array}$} \\
\hline & 1956 & \\
\hline \multirow{2}{*}{ 4a FASE } & 1960 & \multirow{2}{*}{$\begin{array}{l}\text { Fase identificada pela campanha televisiva e recursos para reconstrução } \\
\text { das cidades. Inicia-se um ideal de reestruturaçáo }\end{array}$} \\
\hline & 1976 & \\
\hline \multirow{2}{*}{ 5a FASE } & 1980 & \multirow{2}{*}{$\begin{array}{l}\text { Fase marcada pela divisão mundial em unidades bipolares gerando conse- } \\
\text { qüências nos Jogos Olímpicos pela descontinuidade histórica }\end{array}$} \\
\hline & 1984 & \\
\hline \multirow{2}{*}{ 6a FASE } & 1988 & \multirow{2}{*}{$\begin{array}{l}\text { Início da fase dos Grandes Projetos Olímpicos moldados por um ideal de } \\
\text { transformaçáo de cidade e financiamentos globais }\end{array}$} \\
\hline & 2016 & \\
\hline
\end{tabular}

FONTE ADAPTADO DE RAEDER, 2010

Os Jogos Olímpicos até 1956 se constituíam majoritariamente de baixos investimentos e pequenas alteraçôes urbanas. Entretanto, após 1960 os benefícios midiáticos de exploraçáo do Evento converteram-se em estruturas urbanas, produzindo efeitos nas fases subsequentes. Este fenômeno é explicado dentro de um contexto global com capitais de investimento privado e com a associaçáo de forças de locais a fim de promover uma imagem de cidade a ser comercializada. Neste sentido a Olimpíada de Barcelona, em 1992, tornou-se um exemplo emblemático de renovação urbana por meio de uma gestáo baseada na implementaçáo de um Megaevento esportivo, almejado se beneficiar de possíveis resultados positivos gerados a partir da atração de investimentos, difusão da imagem da cidade, dinamização territorial ocasionada pelos novos equipamentos urbanos e pela consolidaçáo da cidade dentro de uma hierarquia global.

$\mathrm{Na}$ fase atual, os Jogos Olímpicos constituem uma das marcas mais reconhecidas do mundo. Os cinco anéis olímpicos são identificados por cerca de $90 \%$ da população mundial (Andranovich, Burbank\&Heying, 2001, p. 114), fato que, associado à recorrência de seu acontecimento, repetindo-se em cada quatro anos, transformam os Jogos em um símbolo social consolidado na sociedade contemporânea. De acordo com Short (2008, p. 323), a participação popular torna-se elemento fundamental para a confirmação do evento, pois legitima sua concepção e seus custos: "a venda dos Jogos é baseada na necessidade das elites da cidade e/ou de governos nacionais, persuadindo residentes e cidadão para apoiar os enormes custos dos Jogos”.

Em meio a um cenário de investimentos internacionais, os governos locais tornam-se parceiros comerciais de iniciativas privadas a fim de garantir possíveis inflexóes urbanas por meio da construçáo de GPUs. Desta forma os Jogos Olímpicos são reconhecidos como catalisadores de iniciativas, assim como se constituem enquanto elementos construtores de uma "cidade de exceção" (Vainer, 2011), pois neste momento o Megaevento torna-se justificativa para uma manipulaçáo legítima da soberania do Estado. 
Se por um lado a somatória das partes interessadas nos Jogos (tanto grupos da iniciativa privada como a sociedade civil e governantes) pode contribuir com uma gestão urbana integrada, unificando diversos grupos de interesses (Andranovich et al., 2001, p. 127) através de um modelo cooperativo contendo políticas compartilhadas que verdadeiramente orientem para objetivos de reforma urbana, por outro lado são recorrentes as iniciativas falhas de programas Olímpicos com um cunho puramente comercial.

Pelas palavras do próprio presidente do Comitê Olímpico Internacional (cor), Jaques Rogge, quando anuncia que "somos apenas uma organização esportiva, não a representação de todas as ongs do mundo" ou utilizando afirmação ainda mais contundente, do Presidente do Comitê de Coordenação do coi, Hein Verbruggen, "é detestável que as Olimpíadas de Pequim sejam usadas como plataforma para grupos com agendas políticas ou sociais" (Raeder, 2008, p. 12), percebemos a desconexão entre as necessidades locais, pautada sobre os pilares da justiça urbana e do direito à cidade, com os interesses comerciais do evento, que busca somente o seu sucesso e sua consequente reprodução.

A reprodução dos Jogos Olímpicos enquanto ferramentas de promoção da cidade orientam a uma condição de marketing global, na qual emergem as conexóes entre realidades locais e o cenário global. A condição de evento mais televisionado no mundo (Short, 2008, p. 324) concede uma característica peculiar as Olimpíadas que tem, então, o mesmo cenário sendo transmitido simultaneamente nas diversas partes do planeta. O imediatismo dos Jogos Olímpicos "reconfigura as identidades nacionais e suas diferenças" (Roche, 2002, p. 3), pois ao mesmo tempo em que globalizamos as individualidades, mostrando ao mundo as particularidades de cada lugar, assumimos individualmente o global, inserindo de forma mais profunda as características de uma cultura de consumo. São exaltados ícones construídos localmente, porém carregados de significados globais de venda, promovendo as grandes empresas patrocinadoras.

\section{Notas finais}

Os Grandes Projetos Urbanos são estruturas diferenciadas na malha urbana, pois buscam alcançar resultados a partir da criação de elementos urbanos inseridos dentro de práticas de acumulação capitalista em um cenário global. Neste sentido orientam-se para o desenvolvimento de demandas locais e internacionais na cidade, cujos benefícios são reduzidos a uma parte pequena da população e que conduzem a processos exógenos das demandas locais, por vezes, canalizando investimentos sociais para outras infraestruturas.

Por esta razão, tornam-se ferramentas da gestão urbana contemporânea muito mais preocupada com a comercialização de uma imagem de cidade, tendo neste processo o Estado como mediador entre as forças de resistência contra a promoção de um cenário urbano comercializado e a constituição de uma cidade orientada pelas demandas da iniciativa privada.

Os Megaeventos esportivos, constituídos por suas infraestruturas e equipamentos urbanos, inicialmente se estabeleceram como parte da retórica do planejamento 
estratégico, no entanto são agora elementos centrais de uma prática de gestão de cidades, constituindo-se como um dos exemplos mais emblemáticos do conceito de empresariamento urbano, cujo valor e simbolismo são intrínsecos à sua existência (Oliveira, 2011, p. 20). Recorrentemente compreendidos por meio de um discurso ufanista, tais eventos são orientados pela prática comercial e pela lógica de grupos privados capazes de garantir benefícios pela simples reprodução de um ideal inventado.

Nesta leitura os Jogos Olímpicos assumem demasiado destaque como política urbana, em virtude da magnitude de seus impactos, assim como pela extensão imagética do evento. A compreensão dos impactos e oportunidades geradas pelas Olimpíadas transformam-na em ferramenta oportuna para governos que buscam uma gestão mais estratégica da cidade, pois atuam como elementos de consolidação de ideais competitivos, sendo simbolicamente fortalecidos dentro de um modelo hegemônico de produção do espaço urbano.

Efetivamente, os Jogos Olímpicos constituem-se como prática importante para o ingresso de cidades no circuito global de valorização e ferramenta oportuna de redenção de cidades decadentes (Short, 2008, p. 2). Esta reprodução de um cenário de competição urbana é definida por Santos (2008, p. 333) como "a máquina de guerra de uma mais-valia universal de impossível medida, e nem por isso menos eficaz." Diante deste contexto de disputa por lugares na hierarquia mundial de cidades a consolidação da polarização mundo entre "a imagem da cidade global e a metáfora do planeta favela" (BRICs, 2011, p. 4) torna-se central.

A promoção dos Jogos Olímpicos representa a consolidação de um discurso hegemônico em escala global, cujo cenário era, anteriormente, restrito aos países centrais. Entretanto a reconfiguração mundial dotou países periféricos, de força política capazes de integrar circuitos de valorização global por meio de instrumentos até entâo restritos aos "países do norte".

Neste contexto os Megaeventos esportivos aparecem recorrentemente em agendas governamentais de países emergentes com objetivo de renovaçáo urbana, todavia os estudos de impactos destes eventos historicamente se concentram em análises restritas a países com malha urbana e estrutura social consolidada. Portanto,o estudo dos impactos deste novo modelo de gestão urbana, que inclui a incorporação de Megaeventos, ainda carece de aprofundamento, tendo em vista o território encoberto por contradiçốes e desconexóes nos quais recentemente se observa a sua implantação.

Todavia o que se pretende é repensar as práticas atuais de políticas urbanas que se estruturem sobre processos comerciais, nos quais a solvência da população seja diretamente proporcional ao direito à cidade. Neste processo, a cidade esvazia-se do sentido de produção do lugar, pois a o valor comercial homogeneíza as diferenças em detrimento de uma condição global, reconstruindo e revitalizando fisicamente novas cidades baseadas em uma ótica externa sobre a busca de um crescimento exógeno, assim, muito mais do que reproduzirmos modelos de gestão urbana, reproduzimos também modelos de exclusão e segregação espacial. 


\section{Referências bibliográficas}

Andranovich, G., Burbank, M. \&Heying, Ch. (2011). Olympic cities: lessons learned from Mega Event politics. Journalof Urban Affairs, 23(2), 113-131. doi: 10.1111/07352166.00079

Arantes, O. (2000). Uma estratégia fatal: a cultura nas novas gestôes urbanas. In: Arantes, O.Vainer, C \& Maricato, E. A cidade do pensamento único: desmanchando consensos. (pp. 11-74) São Paulo: Vozes.

Bonates, M. F. (2009). El Guggenheim y mucho más- urbanismo monumental e arquitetura de grife em Bilbao. Revista Pós, 16(26), 063-091.

Borja, J. (2005). Un futuro urbano con un corazón antiguo. Biblio 3W, Revista Bibliográfica de Geografía y Ciencias Sociales, 10(584). Em http://www.ub.es/geocrit/b3w-584.htm.

BRIC Policy Center - Centro de Estudos e Pesquisas-Bric. (2011). Megacidades na perspectiva do capitalismo global: as novas tecnologias condicionando o desenvolvimento das redes urbanas nos Brics. Policy Briefno. 4. Rio de Janeiro: Núcleo de Desenvolvimento Urbano e Sustentabilidade BRICs Policy Center / Centro de Estudos e Pesquisa BRICs. Em http://bricspolicycenter.org/policy_brief.php

Broudehoux, A. M. (2011). Imagens do poder: Arquiteturas do espetáculo integrado na olimpíada de Pequim. Novos Estudos - CEBRAP, 89, 39-56. http://dx.doi.org/10.1590/ S0101-33002011000100003

Castells, M. \& Borja, J. (1996). As cidades como atores políticos. Novos Estudos - CEBRAP, 45, 152-166. Em http://goo.gl/wM3CN4

Castells, M. \& Borja, J. (2004). Local y Global: question de Lasciudadesem la era informatica. Madrid: Taurus, Pensamientos.

Coriat, B., Saboia, J. L. M. (1988). Regime de acumulação e relação salarial no Brasil: um processo de fordização forçada e contrariada. Ensaios FEE, 9(2), 3-45. Em http:// revistas.fee.tche.br/index.php/ensaios/article/view/1213

De Oliveira, F. L. \& Lima Junior, P. N. (2009). Grandes projetos urbanos: panorama da experiência brasileira. In Congresso da Associação de Estudos Latino Americanos, Rio de Janeiro, jun. 2009. Em http://lasa.international.pitt.edu/members/congresspapers/ lasa2009/files/OliveiraFabricioLeal.pdf

Debord, G. (1997). A sociedade do espetáculo: comentários sobre a sociedade do espetáculo. Río de Janeiro: Contraponto.

Frampton, K. (2008). História crítica da arquitetura moderna. São Paulo: Martin Fontes.

Freire, M. V. \& Ribeiro, D. (2006). Ouro Olímpico: a história do marketing dos aros. Río de Janeiro: Casa da Palavra.

Furtado, C. (1981). O Brasil pós-“milagre” (3a. ed.). Coleção estudos brasileiros no. 54. Río de Janeiro: Paz e Terra.

Güell, J. M. F. (1997). Planificación estratégica de ciudades. Barcelona: Gustavo Gilli.

Harvey, D. (1992). A condição pós moderna: uma pesquisa sobre as origens da mudança cultural. São Paulo: Edições Loyola.

Harvey, D. (1996). Do gerenciamento ao empresariamento: a transformação da administração urbana no capitalismo tardio. Espaço e Debates, 39, 48-64. Em http://bit.ly/QUWR48

Lerner, J. (2003). Acupuntura urbana. Río de Janeiro: Record. 
Lungo, M. (2005). Globalización, grandes proyectos y privatización de la gestión urbana. Mundo Urbano, no. 25 (Universidad Nacional de Quilmes). Em http://mundourbano. unq.edu.ar/index.php/ano-2005/47-numero-25

Lungo, M. (2004). Grandes proyectos urbanos. Serie mayor, no. 24. San Salvador: UCA Editores. Colección Estructuras y Procesos.

Maia, M. F. R. (2011). Algumas reflexôes sobre o papel do Estado. XI Congresso Luso-Afro Brasileiro de Ciências Sociais. Universidade Federal da Bahia, Brasil, agosto, 2011.

Malengreau, R. (2013). Inclusion in a Divided City: The Role of the UPP in Rio de Janeiro's Favelas. Dissertaçáo mestrado,Universidade de Oxford. Oxford: Reino Unido.

Mattei, L. (2012). Desenvolvimento brasileiro no início do século XXI - Crescimento econômico, distribuição de renda e destruiçãoambiental. Um campeãovisto de perto. Uma análise do modelo de desenvolvimento brasileiro (pp. 32-47). Série Democracia. Río de Janeiro: Heinrich Böll Foundation. Em http://br.boell.org/sites/default/files/ downloads/lauro_mattei.pdf

Nobre, E. A. C. (2000). Reestruturação econômica e território: expansão recente do terciário na marginal do rio Pinheiros. Tese doutorado, Universidade de São Paulo (USP).

Oliveira, A. (2011). Megaeventos, crescimento econômico e desigualdades regionais no Brasil. Boletim Regional, v. 13, pp. 18-30.

Powell, K. (2000). City trasformed: urban architecture at the beginning of the 21st century. Nueva York: Neues.

Raeder, S. (2008). Conflitos no ordenamento territorial em sedes de megaeventos esportivos. Esporte e Sociedade, 4(10), 1-29. Em http://www.uff.br/esportesociedade/pdf/ es1005.pdf

Raeder, S. (2010). Planejamento urbano em sedes de megaeventos esportivos. iv Congresso Luso-Brasileiro para o Planeamento Urbano, Regional, Integrado, Sustentável. Universidade do Algarve, Faro, Portugal. Em http://pluris2010.civil.uminho.pt/ Actas/PDF/Paper201.pdf

Roche, M. (2002). Olympic and Sport Mega-Events as Media-Events: Reflections on the globalisation paradigm. Sixth International Symposium for Olympic Research (pp. 1-12), Beijing, 2002.

Sánchez, F., Bienenstein, G., Canto, B. L., Da Cunha Guterman, B., Barros de M. Benedicto, D. \& Picinatto, L. (2004). Produção de sentido e produção do espaço: convergências discursivas nos grandes projetos urbanos. Revista Paranaense de Desenvolvimento, 107, 39-56. Em http://www.ipardes.gov.br/pdf/revista_PR/107/fernanda_outros.pdf

Santos, M. (2008). A natureza do espaço. São Paulo: Edusp.

Sassen, S. (2010). Sociologia da globalização. (Trad. Ronaldo Cataldo Costa). Porto Alegre: Armed.

Seixas, J. (2010). Os mega eventos na cidade: Imagética social, política econômica e governança urbana. Revista e-Metropolis, 1(2), 4-9. Em http://www.emetropolis.net/edicoes/n02_ set2010/e-metropolis_n02_materia-de-capa.pdf

Serra, J. (1998). Ciclos e mudanças na economia brasileira do pós-guerra. In L. Belusso \& R. Coutinhom (Eds.), Desenvolvimento capitalista no Brasil. São Paulo: Editora Brasiliense.

Short, J. R. (2008). Globalization, cities and the Summer Olympics. City Journal, 12(3), 321340. doi: $10.1080 / 13604810802478888$ 
Somekh, N. \& Campos, C. M. (2005). Desenvolvimento local e projetos urbanos. Portal Vitruvius, Arquitextos 059.01, 2005. Em http://www.vitruvius.com.br/revistas/read/ arquitextos/05.059/470

Ultramari, C. \& Rezende, D. (2007). Grandes projetos urbanos: conceitos e referenciais. Ambiente Construido,7(2), 7-14. Em http://goo.gl/5PbJud

Vainer, C. (2011). Cidade de exceção: reflexôes a partir do Rio de Janeiro. Encontro Nacional da Associação Nacional de Pós-Graduação e Pesquisa em Planejamento Urbano e Regional 14. Anais eletrônicos.

Vainer, C. (2003). Utopias urbanas e o desafio democrático. Revista Paranaense de Desenvolvimento, 105, 25-31. Em http://dialnet.unirioja.es/servlet/articulo?codigo=4813369

Vainer, C. (2000). Pátria, empresa e mercadoria: notas sobre a estratégia discursiva do Planejamento Estratégico Urbano. Em Arantes, O.Vainer, C \& Maricato, E. A cidade do pensamento único: desmanchando consensos. (pp. 75-104). São Paulo: Vozes. 
TRIBUNA 